STUDI

FRANCESI

\section{Studi Francesi}

Rivista quadrimestrale fondata da Franco Simone

185 (LXII | II) | 2018

OCTAVE MIRBEAU: UNE CONSCIENCE AU TOURNANT

DU SIEECLE - sous la direction de Ida Merello

\title{
RICCARDO BENEDETTINI, Il corpo in frammenti. Teatro $e$ romanzo in Agota Kristof
}

\section{Stefano Genetti}

\section{(2) OpenEdition \\ Journals}

Edizione digitale

URL: https://journals.openedition.org/studifrancesi/14089

DOI: 10.4000/studifrancesi.14089

ISSN: 2421-5856

Editore

Rosenberg \& Sellier

\section{Edizione cartacea}

Data di pubblicazione: 1 août 2018

Paginazione: 363-364

ISSN: 0039-2944

\section{Notizia bibliografica digitale}

Stefano Genetti, «Riccardo Benedettin, // corpo in frammenti. Teatro e romanzo in Agota Kristof», Studi Francesi [Online], 185 (LXII | II) | 2018, online dal 01 août 2018, consultato il 15 novembre 2021. URL: http://journals.openedition.org/studifrancesi/14089; DOI: https://doi.org/10.4000/studifrancesi. 14089

Questo documento è stato generato automaticamente il 15 novembre 2021.

\section{(c) (1)}

Studi Francesi è distribuita con Licenza Creative Commons Attribuzione - Non commerciale - Non opere derivate 4.0 Internazionale. 


\title{
RICCARDO BENEDETTINI, Il corpo in frammenti. Teatro e romanzo in Agota Kristof
}

\author{
Stefano Genetti
}

\section{NOTIZIA}

RICCARDO BENEDETTINI, Il corpo in frammenti. Teatro e romanzo in Agota Kristof, «Feuillages» 1, Collana del Gruppo di Studio sul Cinquecento Francese, 2016, 145 pp.

1 Nella «Conversazione con Agota Kristof» (pp. 120-132) risalente al 1999 e ripresa in calce agli articoli qui ricomposti in una lettura complessiva dell'opera, l'autrice rievoca gli anni della propria infanzia e della guerra e ripercorre l'itinerario che, con la Rivoluzione del 1956 e dato il coinvolgimento politico del marito, l'ha portata dall'Ungheria alla Svizzera. Dice inoltre delle difficoltà che la scrittrice-operaia, tornata analfabeta in terra straniera, ha incontrato nel passaggio dalla poesia nella lingua madre alla scrittura in francese, teatrale prima, poi narrativa. Se considera Hier il suo libro più marcatamente autobiografico (p. 123), il legame con la patria e con il passato accomuna tutti i suoi scritti. Proprio l'inscrizione del vissuto, e la sua trasfigurazione letteraria, è uno dei fili conduttori dell'argomentazione che l'A., a partire da Le grand cahier (capitolo I), estende alla cosiddetta trilogia (capitolo II), alle novelle (capitolo III) e al teatro: l'inscrizione della sua storia personale, ma anche della Storia, e ciò nonostante la scarsità di indicazioni spazio-temporali precise. A più riprese, l'esilio, per il quale Agota Kristof rimpiangerà di aver optato, viene accostato alle testimonianze della deportazione di Primo Levi o di Charlotte Delbo in nome dello sradicamento violento, della lacerazione traumatica e della sopravvivenza all'intollerabile. Non solo; a essere costante oggetto di riflessione è la tensione tra dimensione realistica, rinforzata dalla preponderanza del concreto sull'emozionale, e dimensione onirica, tra aderenza all'esperienza e «stilizzazione straniante» (p. 22), tra impegno e 
distanziazione spersonalizzata, universalizzante, tra testimonianza mediata e allegoria, fable, mito.

Con svariati riferimenti ad altri scrittori e teorici, a Dostoevskij e a Bataille - tra le letture che, insieme alla Bibbia, maggiormente hanno segnato l'autrice -, a Vercors, Bernhard e Tournier come a Freud, Bachelard, Sartre, Girard o Kristeva, i temi ricorrenti qui messi in rilievo vanno dalla dialettica di verità e menzogna alla coincidenza paradossale di innocenza e atrocità, dai rituali esercizi di crudeltà alle trascrizioni di sogni e al bestiario, felino in particolare, che li popola, dall'insonnia e dal digiuno all'alcol, alla follia e al suicidio, dalla mostruosità declinata nelle sue varianti letterali e metaforiche alla centralità dell'infanzia e di motivi quali l'abbandono, l'incesto, il tradimento, il supplizio e la vendetta, dalla tensione fra unità e duplicità in merito al nous autodiegetico dei gemelli di Le grand cahier - all'invenzione dell'altro e alla scrittura come mezzi di resistenza in un universo dominato dalla violenza, dall'isolamento e dalla sofferenza. Nel capitolo IV ci si sofferma sulle disfunzioni comunicative e relazionali a proposito dei venticinque brevi racconti riuniti in C'est égal e dell'umorismo nero, della latente ironia che li caratterizza. Tra fantasmi e fantasie, trasgressione e profanazione, zoofilia e tortura, la spettacolarizzazione del godimento attraverso il dolore e la copresenza di impassibilità affettiva ed esperienze sessuali estreme costituiscono l'argomento del capitolo V, il nesso tra erotismo e frenesia (auto)distruttiva implicando talora, come nel caso dell'ufficiale pederasta e sadomasochista, la denuncia della guerra e del totalitarismo.

I drammi, anche radiofonici, raccolti in L'heure grise e in Le monstre così come la pièce rinnegata dall'autrice Monsieur Klapek et la solitude sono oggetto di analisi nel capitolo $\mathrm{VI}$, dove viene mostrato, tramite osservazioni riguardanti la gestione dello spazio scenico oppure l'alternanza di dialoghi e passi corali lirico-descrittivi, come Agota Kristof si ricolleghi a una drammaturgia arcaica e, più in generale, a una visione tellurica, viscerale e sacrale del teatro. Non solo la protagonista amputata di La clé de l'ascenseur incarna il corpo in frammenti del titolo, ma questo percorso a ritroso nell'opera di Agota Kristof illustra i molti aspetti - l'atmosfera da incubo, la crudeltà e lo straniamento, il doppio e la maschera - che nella scrittura drammatica preludono alla narrativa, a cominciare dalle saynètes del primo romanzo. Ricordata fin da principio e ammessa dall'autrice stessa nell'intervista (p. 122), questa matrice teatrale è uno degli elementi che, sparsi nelle diverse sezioni, ribadiscono la profonda unità del suo itinerario creativo.

4 Corredato di una ricca bibliografia critica, il saggio è consultabile sul sito: http:// www.cinquecentofrancese.it/index.php/feuillages/263-feuillages-n-1-riccardobenedettini-il-corpo-in-frammenti-teatro-e-romanzo-in-agota-kristof. 